pharmaceutical companies, including Eli Lilly and Company. This specific analysis and abstract was supported by Eli Lilly and Company.

Disclosure of Interest: R. Moon: None declared, J. Hill Grant/research support from: Eli Lilly and Company, Employee of: Eli Lilly and Company, N. Booth: None declared, S. Lobosco: None declared

DOI: 10.1136/annrheumdis-2018-eular.7341

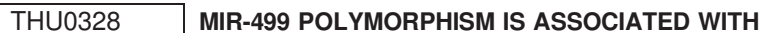 SUSCEPTIBILITY TO PSORIATIC ARTHRITIS - PRELIMINARY STUDY}

${ }^{1}$ R. Sokolik, J. Swierkot ${ }^{1}$, M. Iwaszko ${ }^{2}$, M. Kozlowski ${ }^{2}$, L. Korman ${ }^{1}$, P. Wiland ${ }^{1}$, K. Bogunia-Kubik ${ }^{2} .{ }^{1}$ Department of Rheumatology and Internal Medicine, Medical University; ${ }^{2}$ Laboratory of Clinical Immunogenetics and Pharmacogenetics, Hirszfeld Institute of Immunology and Experimental Therapy, Polish Academy of Sciences, Wroclaw, Poland

Background: Polymorphism within the miR-499 has been reported to be associated with susceptibility to rheumatoid arthritis (RA) in various populations.

Objectives: Our study aimed to find out whether similar association could be observed also in Polish population in both RA and psoriatic arthritis (PsA) patients.

Methods: For this purpose 359 individuals were studied, including 111 RA patients, 86 patients with PsA and 162 healthy blood donors that served as a control group.

Genotyping for miR-499 rs3746444 T/C was performed using a LightSNiP assay. Results: Distribution of the miRNA-499 alleles and genotypes was similar in RA patients and controls. Among RA patients those carrying the CC homozygous genotype presented with lower DAS28 at diagnosis (0.027) but higher CRP levels after 12 weeks of anti-TNF treatment $(\mathrm{p}=0.042)$.

Interestingly, the TT genotype (rs3746444) was overexpressed in patients with PsA as compared to controls ( $O R=1.85, p=0.034$ ) but its frequency was not significantly different when compared to RA cases. This polymorphism was also not found to be associated with clinical parameters in PsA patients.

Conclusions: These results show that miR-499 rs3746444 T/C polymorphism may constitute a risk factor for psoriatic arthritis development.

Acknowledgements: This work was supported by the NCN 2016/21/B/NZ5/ 01901 project.

Disclosure of Interest: None declared

DOI: 10.1136/annrheumdis-2018-eular.6455

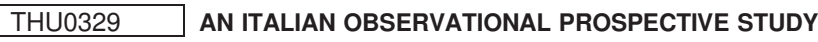 ON PREDICTORS OF CLINICAL RESPONSE TO GOLIMUMAB AT 6 MONTHS IN PATIENTS WITH ACTIVE PSORIATIC ARTHRITIS}

${ }^{1}$ R. Scrivo, A. Giardino ${ }^{2}$, C. Salvarani ${ }^{3}$, R. Foti $^{4}$, A. Afeltra ${ }^{5}$, O. Viapiana ${ }^{6}$, F. Salaffi ${ }^{7}$, F. lannone ${ }^{8}$, on behalf of the Predicting MDA in PsA Study Group. ${ }^{1}$ Medicina Interna e Specialità Mediche, Sapienza Università di Roma; ${ }^{2}$ MSD Italia S.r.l., Rome; ${ }^{3}$ University of Modena and Reggio Emilia, Reggio Emilia; ${ }^{4}$ A.O.U. Policlinico V. Emanuele, Catania; ${ }^{5}$ Campus Bio-Medico, Rome; ${ }^{6}$ University of Verona, Verona; ${ }^{7}$ Politecnica University of Marche, Jesi; ${ }^{8}$ University of Bari, Bari, Italy

Background: The identification of markers of response to biologic agents in the treatment of active psoriatic arthritis (PsA) may help in predicting the outcome and hence in optimising therapy.
Objectives: To evaluate the ability of a panel of candidate factors to predict the clinical response, defined as the achievement of minimal disease activity (MDA) following 6 month therapy with golimumab.

Methods: This Italian 6 month observational study included 149 PsA patients (53.7\% males, mean age 49 years (SD 11) inadequate responders to conven tional therapies who started the anti-tumour necrosis factor- $\alpha$ golimumab. Estimated factors included demographic data and baseline characteristics of the disease, measures of disease activity and functional disability, and biomarkers.

Results: At 6 months, a high rate of treatment persistency $(80 \%)$ was observed. MDA was achieved in $44.3 \%$ of patients. Multivariate analysis showed Disease Activity in Psoriatic Arthritis (DAPSA) score, high-sensitivity C-reactive protein (hs-CRP), age, and disease duration as baseline factors correlating with MDA achievement at 6 months (table 1). A higher hs-CRP value and the absence of comorbidities were predictive factors for MDA at 6 months in biomarker-enhanced prediction models.

Golimumab was effective in improving disease and functional parameters and was well tolerated.

Conclusions: The availability of predictive factors of treatment response identified in this study may be helpful in driving the selection of PsA patients that are most likely to benefit of the therapy with golimumab.

Disclosure of Interest: R. Scrivo Consultant for: Abbvie, MSD, Celgene, Jans sen, A. Giardino Employee of: MSD, C. Salvarani: None declared, R. Foti: None declared, A. Afeltra: None declared, O. Viapiana Consultant for: Novartis, Ely Lilly, Sanofi Genzyme, F. Salaffi: None declared, F. lannone Speakers bureau: Abbvie, Actelion, BMS, Lilly, Novartis, MSD, Pfizer, UCB, Janssen, Celgene, Roche, Sanofi

DOI: 10.1136/annrheumdis-2018-eular.3666

\section{THU0330 \\ OBESITY IN PSORIATIC ARTHRITIS: COMPARATIVE PREVALENCE WITH SKIN PSORIASIS AND ASSOCIATED FACTORS}

R. Queiro, A. Lorenzo, E. Pardo, A. Brandy, S. Alonso, M. Alperi, L. Arboleya

J. Ballina. Rheumatology, Hospital Universitario Central De Asturias, Oviedo, Spain

Background: Obesity $\left(\mathrm{BMI} \geq 30 \mathrm{~kg} / \mathrm{m}^{2}\right.$ ) is a common cardiovascular risk factor in psoriatic disease ${ }^{1}$. Although the prevalence of obesity is high, the factors associated with it in psoriatic arthritis (PSA) are poorly understood.

Objectives: We aimed to evaluate the prevalence and obesity-associated factors in patients with PsA.

Methods: Retrospective cross-sectional study that included 205 consecutive patients with PsA according to CASPAR criteria. The prevalence of obesity was compared with that of 310 patients with skin psoriasis of similar age ( \pm 3 years). The factors associated with obesity were first analysed by a conditional logistic regression. The significant factors in this first model were then introduced in a multivariate model using a backward step approach ( $p$-values $<0.05$ were considered significant)

Results: One-hundred twelve men and 94 women were included, with a mean age of $53 \pm 13$ years. Obesity was more prevalent among psoriatics $(36.5 \%) \mathrm{com}$ pared to PsA patients (24\%), OR $1.6(1.1-2.3), \mathrm{p}<0.05$. The factors associated with obesity in the univariate analysis $(p<0.05)$ were: onset of psoriasis $>40$ years (OR 2.4), onset of arthritis $>40$ years (OR 2.1), PsA family history (OR 3.1), polyarticular presentation (OR 1.9), axial presentation (OR 2.5), polyarticular evolution (OR 2.4), axial evolution (OR 4.2), diabetes (OR 3.6), HBP (OR 3.9), and dyslipidemia (OR 3.5). After correcting for age, sex, disease duration and other confounders, independent associations with obesity found in the multivariate mode ( $p<0.05$ ) were: PsA family history (OR 3.6, IC95\%: 1.1-14.4), axial evolution (OR 4.4, IC95\%: 1.0-22.4) and dyslipidemia (OR 3.5, IC95\%: 1.5-8.6).

\begin{tabular}{|c|c|c|c|c|c|}
\hline Used model & Parameter & $\begin{array}{c}\text { Item } \\
\text { considered }\end{array}$ & $\begin{array}{l}\text { Odd } \\
\text { Ratio }\end{array}$ & $\begin{array}{c}95 \% \text { confidence } \\
\text { interval }\end{array}$ & $P$ value \\
\hline \multirow[t]{7}{*}{ Univariate logistic model (ULM) } & Gender & Female & 0.3197 & $0.1531-0.6677$ & 0.0024 \\
\hline & Age & Continuous & 0.9570 & $0.9252-0.9899$ & 0.0109 \\
\hline & Baseline DAPSA score & Continuous & 0.9287 & $0.8967-0.9618$ & $<0.0001$ \\
\hline & $\begin{array}{l}\text { Baseline HAQ total } \\
\text { score }\end{array}$ & Continuous & 0.2937 & $0.1423-0.6063$ & 0.0009 \\
\hline & Baseline Pain & Continuous & 0.9833 & $0.9684-0.9984$ & 0.0299 \\
\hline & Baseline BASDAI & Continuous & 0.7036 & $0.5733-0.8635$ & 0.0008 \\
\hline & Comorbidities & Presence & 0.3258 & $0.1465-0.7241$ & 0.0059 \\
\hline Multivariate logistic model & Age & Continuous & 0.9542 & $0.9112-0.9993$ & 0.0465 \\
\hline \multirow[t]{3}{*}{ (MLM) } & Baseline hs-CRP & Continuous & 1.0015 & $1.0002-1.0028$ & 0.0241 \\
\hline & Baseline DAPSA score & Continuous & 0.9255 & $0.8879-0.9647$ & 0.0003 \\
\hline & Disease duration & Continuous & 1.0057 & $1.0007-1.0107$ & 0.0260 \\
\hline Biomarker-enhanced ULM & Baseline hs-CRP & Continuous & 1.0688 & $1.008-1.1334$ & 0.0261 \\
\hline \multirow[t]{2}{*}{ Biomarker-enhanced MLM } & Comorbidities & Presence & 0.2645 & $0.0881-0.7941$ & 0.0177 \\
\hline & Baseline DAPSA score & Continuous & 0.9231 & $0.8850-0.9628$ & 0.0002 \\
\hline
\end{tabular}


Conclusions: Obesity was more common among our patients with cutaneous psoriasis than in those with arthritis. The model that best explains obesity in this PsA series combines genetic factors (PsA family history), together with factors specific to the metabolic syndrome (dyslipidemia), with others owned to arthritis (axial evolution).

\section{REFERENCE:}

[1] Husni ME. Comorbidities in psoriatic arthritis. Rheum Dis Clin North Am 2015;41:677-98.

Disclosure of Interest: None declared

DOI: 10.1136/annrheumdis-2018-eular.2947

\section{\begin{tabular}{|l|l}
\hline THU0331 RELATIONSHIP BETWEEN THE NAIL \\
\hline
\end{tabular} ULTRASONOGRAPHIC EVALUATIONS AND CLINICAL FEATURES IN PATIENTS WITH PSORIATIC ARTHRITIS}

S. Acer, H.S. Baklacıoğlu, D. Erdem, M.T. Duruöz. Physical Treatment and Rehabilitation Department, Rheumatology Division, Marmara University, Istanbul, Turkey

Background: Nail ultrasonography (US) is a favourable visualisation method to evaluate the subunits of the nail. Little is known about the relation between the properties of nail structures and the clinical characteristics of patients with psoriatic arthritis (PsA).

Objectives: To show the relationship between the clinical features and ultrasonographic evaluations of the nail in patients with PSA.

Methods: Patients with PSA according to the CASPAR criteria were recruited into the study. All of the hand nails and toenails were examined by grayscale and power Doppler techniques. The relations between the characteristics of the patients and the sonographic findings of the nail structures were assessed. Concerning to patient characteristics, subtypes of PsA, gender, age, height, BMI, working status, smoking, PsA duration, psoriasis duration, history of dactylitis, history of uveitis, number of tender and swollen joints, Maastricht Ankylosing Spondylitis Enthesitis Score, CRP, disease activity, haemoglobin, sacroiliitis, inspectional nail involvement (INI), Nail Psoriasis Severity Index (NAPSI), PASI, $H A Q$, quality of life, and the biologic treatment were recorded. The nail plate thickness (NPT), number of nails with trilaminar irregularity (NTI), nail bed thickness (NBT), and the doppler activity score (DAS) were recorded as the sonographic nail findings. The Kruskal Wallis analysis, Spearman's correlation, and Man Whitney $U$ tests were used in statistical analysis. $p<0.05$ was accepted as significant. Results: 63 patients (756 nails) were evaluated. Among the PsA subtypes, 38\% of patients were asymmetrical oligoarticular arthritis, $38 \%$ were symmetrical polyarthritis, $7.9 \%$ distal interphalangeal arthropathy, and $15.8 \%$ predominant spondylitis. All of the ultrasonographic nail parameters were independent of the PsA subtypes $(p>0.05)$. The mean of NPT was higher in males and correlated with age, height, and the haemoglobin levels. The NTI score was higher in patients with INI and correlated with the NAPSI score. The mean of NBT was only correlated with the haemoglobin levels. The DAS was higher in workers and correlated with age and the NAPSI score. The other clinical parameters were not associated with the sonographic findings.

Abstract THU0331 - Table 1. Relationships between the patients' characteristics and the ultrasonographic parameters*

\begin{tabular}{|l|l|l|l|l|l|l|l|}
\hline $\begin{array}{l}\text { US nail } \\
\text { parameters }\end{array}$ & Gender & Worker & INI & Age & Height & NAPSI & Hemoglobin \\
\hline NPT (mm) & $p=0.002$ & & & $\begin{array}{l}p=0.001 \\
\text { rho:0.396 }\end{array}$ & $\begin{array}{l}p=0.021 \\
\text { rho:0.290 }\end{array}$ & & $\begin{array}{l}p=0.021 \\
\text { rho:0.292 }\end{array}$ \\
\hline NTI (0-12) & & & $p<0.0001$ & & & $\begin{array}{l}p<0.0001 \\
\text { rho:0.668 }\end{array}$ & \\
\hline NBT (mm) & & & & & & & $\begin{array}{l}p=0.012 \\
\text { rho:0.316 }\end{array}$ \\
\hline DAS (0-48) & & $p=0.042$ & & $\begin{array}{l}p=0.001 \\
\text { rho:-0.407 }\end{array}$ & & $\begin{array}{l}p=0.006 \\
\text { rho:0.344 }\end{array}$ & \\
\hline
\end{tabular}

(US: ultrasonography, INI: inspectional nail involvement, NAPSI: nail psoriasis severity index, NPT: nail plate
thicknes, NTI: nails with trilaminar irregularity, NBT: nail bed thickness, DAS: doppler activity score. ${ }^{*}$ Only parameters which have statistical significant relations by Mann Whitney U test and Spearman's correlation).

Conclusions: The ultrasonographic findings of the nail structures were determined in PsA. These findings did not differ among the subtypes of the disease. Although the sonographic nail findings were not associated with the most of the clinical parameters; they had significant relations with some demographics, inspectional nail involvements, and haemoglobin levels in PsA.

\section{REFERENCE:}

[1] Acquitter M, Misery L, Saraux A, Bressollette L, Jousse-Joulin S. Detection of subclinical ultrasound enthesopathy and nail disease in patients at risk of psoriatic arthritis. Joint Bone Spine 2017:84(6):703-707.

Disclosure of Interest: S. Acer: None declared, H. S. Baklacıoğlu: None declared, D. Erdem: None declared, M. T. Duruöz Grant/research support from: Abbvie, Consultant for: Novartis, Speakers bureau: Abdi ıbrahim DOI: 10.1136/annrheumdis-2018-eular.4511

\section{THU0332 FATIGUE REMAINS A DOMINATNG SYMPTOM DESPITE TUMOUR NECROSIS FACTOR INHIBITOR THERAPY IN PSORIATIC ARTHRITIS: A POPULATION-BASED COHORT STUDY}

${ }^{1}$ T.S. Jørgensen, M. Skougaard ${ }^{1}$, C. Ballegaard ${ }^{1}$, P. Mease ${ }^{2}$, V. Strand ${ }^{3}$, L. Dreyer ${ }^{4}$, L.E. Kristensen ${ }^{1} .{ }^{1}$ The Parker Institute, Copenhagen University Hospital, Bispebjerg and Frederiksberg, Copenhagen F, Denmark; ${ }^{2}$ Swedish Medical Center and University of Washington, Seattle; ${ }^{3}$ Division Immunology/ Rheumatology, Stanford University, Palo Alto, USA; ${ }^{4}$ Center for Rheumatology and Spine Diseases, Rigshospitalet-Gentofte, Copenhagen, Denmark

Background: Psoriatic arthritis (PsA) is a chronic inflammatory disorder associated with fatigue, pain and impaired function. Tumour necrosis factor inhibitor (TNFi) therapy fails among half of patients with PsA treated in routine care.

Objectives: The objective of this population-based cohort study was to investigate the association of fatigue with disease activity and adherence to therapy in PsA patients receiving their first TNFi.

Methods: Data on patient characteristics, disease activity and treatment adherence were obtained from the DANBIO register. Information on comorbidities according to the Charlson Comorbidity Index $(\mathrm{CCl})$ and psychiatric comorbidities was obtained through linkage with the Danish National Patient Register. We performed Kaplan-Meier plots and univariate Cox proportional hazard regression analysis. Percentages of patients achieving relevant clinical responses were calculated.

Results: From 2006 thru 2016, we identified 880 patients eligible for analyses Patients with upper median fatigue scores had statistically significantly higher disease activity measures, higher pain and $\mathrm{HAQ}$ scores, more comorbidities and current smoking status at baseline compared with patients with lower median fatigue scores (table 1). After treatment initiation the mean VAS fatigue score decreased from $62 \mathrm{~mm}(\mathrm{SD} 25)$ to $44 \mathrm{~mm}(\mathrm{SD} 30)$ at six months $(\mathrm{p}<0.001)$. Kaplan-Meier curves showed shorter adherence to treatment in patients with higher baseline fatigue scores compared with patients with lower fatigue scores (HR 1.43 [1.2 to 1.7], $\mathrm{p}<0.001$ ) (figure 1). ACR20, 50 and 70 responses at six months were $49 \%$ $35 \%$ and $18 \%$ respectively. VASfatigue 20,50 and 70 responses were $57 \%, 39 \%$ and $20 \%$, respectively. The kappa value between ACR20, 50, 70 and VASfatigue responses were $0.37,0.40$ and $0.48(p<0.001)$, respectively.

Abstract THU0332 - Table 1. Baseline characteristics according to median fatigue stratification

\begin{tabular}{lccc}
\hline & $\begin{array}{c}\text { Lower median } \\
\text { VAS fatigue } \\
(\mathbf{n}=\mathbf{4 3 0 )}\end{array}$ & $\begin{array}{c}\text { Upper median } \\
\text { VAS fatigue } \\
(\mathbf{n}=\mathbf{4 5 0})\end{array}$ & $\mathrm{p}$ value \\
\hline Age, years & $47.8(39.4-$ & $49.0(40.0-$ & $\mathrm{p}=0.905$ \\
Male gender & $57.3)$ & $56.1)$ & \\
DAS28-CRP (0-10) & $51 \%$ & $40 \%$ & $\mathrm{p}<0.001$ \\
HAQ score (0-3) & $4.0(3.2-3.7)$ & $4.8(3.9-5.5)$ & $\mathrm{p}<0.001$ \\
& $0.75(0.38-$ & $1.38(0.88-$ & $\mathrm{p}<0.001$ \\
VAS patient pain (0-100) & $1.13)$ & $1.75)$ & \\
BMI & $45(29-62)$ & $74(63-84)$ & $\mathrm{p}<0.001$ \\
& $26.8(23.7-$ & $27.7(24.3-$ & $\mathrm{p}=0.118$ \\
Current smoking & $30.7)$ & $31.2)$ & \\
Comorbidities (\%) & $28 \%$ & $36 \%$ & $\mathrm{p}=0.034$ \\
CCl=0 & $66 \%$ & $61 \%$ & $\mathrm{p}=0.049$ \\
CCl=1 & $27 \%$ & $27 \%$ & \\
CCl $\geq 2$ & $7 \%$ & $12 \%$ & \\
Depression treated in hospital, $n$ & $18(4.2)$ & $31(6.8)$ & $\mathrm{p}=0.105$ \\
(\%) & & & \\
\hline
\end{tabular}

Values are the mean and SD except where stated otherwise. Comparisons were assessed by $X^{2} /$ Mann-Whitney test. Lower median fatigue $<64 \mathrm{~mm}$, higher median fatigue $>64 \mathrm{~mm}$ 